\title{
Comparative Immunological Relationships of Two Distinct Sets of Isofunctional Dehydrogenases in the Genus Leuconostoc
}

\author{
MIREILLE HONTEBEYRIE AND FRANCIS GASSER \\ Service de Physiologie Cellulaire, Institut Pasteur, 75015 Paris, France
}

\begin{abstract}
D-Lactate dehydrogenase (D-LDH) and glucose-6-phosphate dehydrogenase (G-6-P-DH), both purified from Leuconostoc lactis strain NCDO 546, were used to prepare specific antisera. Cross-reactions of varying intensity with the anti-DLDH were obtained with all of the Leuconostoc strains and with certain strains of the heterofermentative lactobacilli studied. Cross-reactions with the anti-G-6P-DH were obtained with all of the Leuconostoc strains except those of $L$. oenos; none of the heterofermentative lactobacilli cross-reacted. Pairwise comparisons between cross-reacting extracts with respect to each antiserum permitted the assignment of strains to groups of identical immunological specificity: with the exception of a single strain, the groups of strains revealed by the use of each antiserum coincided.
\end{abstract}

It has become evident in recent years $(1,14$, $15,17,18)$ that comparative immunological studies of specific enzymes can provide valuable information about the taxonomic and evolutionary structure of relatively large living groups. Such studies have been particularly extensive among the lactic acid bacteria (7, 10-12). Analysis of immunological cross-reactivity of isofunctional enzymes of many different species by double diffusion shows that the strains tested can be assembled in groups that share an identical immunological specificity for each particular enzyme. However, since enzymes may evolve at different rates, it is not evident a priori that comparative immunological studies of several different isofunctional enzymes synthesized by a given set of bacterial strains will permit assignment of these strains to the same groups of identical immunological specificity. To examine this question, we have conducted a comparative study of two enzymes: the D-lactate dehydrogenase (D-LDH, EC 1.1.1.28) and the glucose-6-phosphate dehydrogenase (G-6-P-DH, EC 1.1.1.49) of the genus Leuconostoc. Antisera prepared against enzymes isolated from a single strain of Leuconostoc lactis (NCDO 546) were employed. This strain was chosen as an immunological reference point because cross-reactions between its D-LDH and antisera directed against the $\mathrm{D}$ LDHs of three Lactobacillus species had been observed previously (7).

\section{MATERIAL AND METHODS}

Bacterial strains and growth media. The bacterial strains used are listed in Table 1. Cultures of most strains were grown in 2-liter Fernbach flasks containing $500 \mathrm{ml}$ of MRS medium (2), aerated by shaking in air at $30 \mathrm{C}$, and the cells were harvested by centrifugation at the end of the exponential phase. To obtain adequate cell yields of Leuconostoc oenos strains, the MRS medium was prepared with ribose $(10 \mathrm{~g} /$ liter $)$ in place of glucose and adjusted with lactic acid to $\mathrm{pH} 5$; the cultures were incubated at $30 \mathrm{C}$ for 2 to 3 days without shaking in $750-\mathrm{ml}$ Erlenmeyer flasks containing $500 \mathrm{ml}$ of medium.

Assay and preparation of enzymes. The cells were washed twice in Tris-hydrochloride buffer $[50 \mathrm{mM}$ tris(hydroxymethyl)aminomethane adjusted to $\mathrm{pH} 8$ with $\mathrm{HCl}$ ] and resuspended in a buffer solution (20 $\mathrm{mM}$ Tris-hydrochloride, $1 \mathrm{mM}$ ethylenediaminetetraacetic acid, $1 \mathrm{mM}$ dithiothreitol, $\mathrm{pH} 7.2$ ) at a concentration of $1 \mathrm{~g}$ (wet weight) of cells per $10 \mathrm{ml}$. The cell-free extracts were prepared by treatment with a Branson sonifier type B-12 for 20 to $40 \mathrm{~min}$ and clarified by centrifugation at $4 \mathrm{C}$ for $20 \mathrm{~min}$ at 31,000 $\times g$.

Assays of D-LDH and G-6-P-DH were performed by previously described methods (9). The two enzymes were separated and purified from L. lactis NCDO 546 as previously described (9).

Immunological procedures. Antisera directed against the pure D-LDH and G-6-P-DH of L. lactis NCDO 546 were prepared in male New Zealand white rabbits; two rabbits were immunized with each enzyme. The immunization schedule began with four intradermal injections over a 4-week period. Each injection consisted of $80 \mu \mathrm{g}$ of enzyme and $50 \mu \mathrm{g}$ of methylated bovine serum albumin (13) in a volume of $0.25 \mathrm{ml}$, mixed with an equal volume of complete Freund adjuvant (Difco). Ten days after the last intradermal injection, each animal received an intravenous injection of $200 \mu \mathrm{g}$ of enzyme and $150 \mu \mathrm{g}$ of methylated bovine serum albumin in $1 \mathrm{ml}$ of physiological saline $(\mathrm{pH} 7)$. The rabbits were bled 10 days after this injection, and the sera were pooled and stored at $4 \mathrm{C}$ in the presence of $\mathrm{NaN}_{3}(0.04 \%)$.

Immunoelectrophoresis experiments were con- 
TABLE 1. Bacterial strains studied ${ }^{a}$

\begin{tabular}{|c|c|c|c|c|c|}
\hline Organisms & Strain & Origin & Organisms & Strain & Origin \\
\hline \multirow[t]{2}{*}{ Leuconostoc cremoris } & 543 & NCDO & \multirow[t]{13}{*}{ Leuconostoc mesenteroides } & 10830 & ATCC \\
\hline & 829 & NCDO & & 1533 & NCDO \\
\hline \multirow[t]{9}{*}{ Leuconostoc lactis } & 532 & NCDO & & 768 & NCDO \\
\hline & 533 & NCDO & & 8710 & NCIB \\
\hline & 534 & NCDO & & 9317 & NCIB \\
\hline & 535 & NCDO & & 882 & NCDO \\
\hline & 536 & NCDO & & 9319 & NCIB \\
\hline & 546 & NCDO & & 3351 & NCIB \\
\hline & 549 & NCDO & & V 16 & \\
\hline & 956 & NCDO & & $512-13$ & \\
\hline & 959 & NCDO & & $512-17$ & \\
\hline \multirow[t]{9}{*}{ Leuconostoc paramesenteroides } & 803 & NCDO & & $513-7$ & \\
\hline & 870 & NCDO & & 513-12 & \\
\hline & 871 & NCDO & \multirow[t]{5}{*}{ Leuconostoc oenos } & WL D 1 & M. Rogosa \\
\hline & 872 & NCDO & & WL BG 31 & M. Rogosa \\
\hline & 873 & NCDO & & WL B 6 & M. Rogosa \\
\hline & 885 & NCDO & & WL LA 1 & M. Rogosa \\
\hline & 886 & NCDO & & $\mathrm{SC} 122$ & M. Rogosa \\
\hline & 955 & NCDO & \multirow[t]{2}{*}{ Lactobacillus brevis } & 391 & NCDO \\
\hline & 54169 & CIP & & 14869 & ATCC \\
\hline \multirow[t]{7}{*}{ Leuconostoc dextranicum } & 517 & NCDO & \multirow{3}{*}{$\begin{array}{l}\text { Lactobacillus buchneri } \\
\text { Lactobacillus fermenti }\end{array}$} & 110 & NCDO \\
\hline & 812 & NCDO & & 236 & CNRZ \\
\hline & 529 & NCDO & & 14931 & ATCC \\
\hline & 2706 & NCIB & Lactobacillus viridescens & V1 & \\
\hline & 3356 & NCIB & Lactobacillus jensenii & 25258 & CIP \\
\hline & 3739 & NCIB & $\begin{array}{l}\text { Heterofermentative } \\
\text { lactobacilli: }\end{array}$ & & \\
\hline & & & HL. I (6) & 23272 & ATCC \\
\hline \multirow[t]{6}{*}{ Leuconostoc mesenteroides } & 54168 & CIP & & $61 \mathrm{AC}$ & F. Gasser \\
\hline & 54170 & CIP & & $65 \mathrm{~A}$ & F. Gasser \\
\hline & 54171 & CIP & HL II (6) & $61 \mathrm{AZ}$ & F. Gasser \\
\hline & 8013 & NCIB & & V 193 & J. Peynaud \\
\hline & 522 & NCDO & HL III (6) & $61 \mathrm{H}$ & F. Gasser \\
\hline & 523 & NCDO & & F 15 & M. E. Sharpe \\
\hline
\end{tabular}

${ }^{a}$ ATCC, American Type Culture Collection; CIP, Collection de l'Institut Pasteur; CNRZ, Centre National de Recherche Zootechnique; NCDO, National Collection of Dairy Organisms; NCIB, National Collection of Industrial Bacteria. Type or reference strains are italicized.

ducted by the method of Grabar and Williams (8) using agarose gel in barbital buffer, $\mathrm{pH} 8.2$.

Immunodiffusion tests were performed as described by Gasser and Gasser ( 7$)$, using undiluted antisera ( 30 $\mu$ liters for anti-D-LDH and $60 \mu$ liters for anti-G-6-PDH) in the inner well. The outer wells received a quantity of crude extract containing about 0.5 unit of enzymatic activity. Analysis and presentation of the results were made as proposed by Gasser and Gasser (7).

\section{RESULTS}

Upon electrophoresis, the pure D-LDH and G-6-P-DH preparations each yielded a single spot of activity revealed by the method of Fine and Costello (3), and these were located opposite a single precipitin line when their respective antisera were placed in a lateral channel. A crude extract of $L$. lactis NCDO 546 also yielded a single precipitin line when tested by immunoelectrophoresis with each antiserum (Fig. 1). There was no detectable cross-reactivity between the two enzymes.
Double diffusion experiments showed that extracts of all the strains of Leuconostoc listed in Table 1 cross-react with the anti-D-LDH, except strains NCDO 955 and CIP 54169. No D-LDH activity could be detected in crude extracts of these strains. We may note that the same extracts produced a line of precipitate against serum anti-G-6-P-DH.

The cross-reactions observed with the anti-DLDH permit a division of the Leuconostoc strains examined into seven groups of identical specificity (Table 2). The homologous group A comprised all strains of $L$. lactis; when crude extracts of these strains were placed in two adjacent wells in an Ouchterlony plate, their precipitin lines fused without a spur. Extracts of all the other strains were heterologous, since they gave a spur against the extracts of any strain of group $A$, including NCDO 546. The heterologous strains were divided into six groups of identical specificity- $B, C, D, E, F, G$. Extracts of strains of each of these groups produced a continuous precipitin line without 


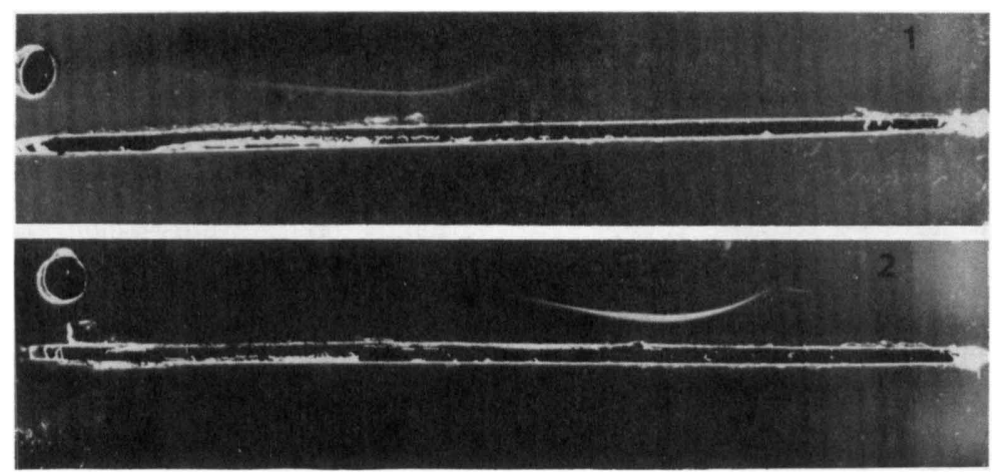

Fig. 1. Immunoelectrophoresis of a crude extract (150 $\mu \mathrm{g}$ of proteins) of Leuconostoc lactis NCDO 546 with anti-D-LDH (1) and anti-G-6-P-DH (2) (400 $\mu$ liters of each antiserum).

TABLE 2. Groups of identical immunological specificity determined by the anti-D-LDH serum and the anti-G-6-P-DH of Leuconostoc lactis NCDO 546

\begin{tabular}{|c|c|c|c|c|}
\hline $\begin{array}{l}\text { Immuno- } \\
\text { logical } \\
\text { results of } \\
\text { D-LDHs }\end{array}$ & Strains & $\begin{array}{l}\text { Immuno- } \\
\text { logical } \\
\text { results of } \\
\text { G-6-P-DHs }\end{array}$ & \multicolumn{2}{|c|}{ Groups from Garvie $(4,5)$} \\
\hline$A$ & $\begin{array}{l}\text { NCDO } 532,533,534,535,536 \\
\quad 546,549,956,959\end{array}$ & $a$ & L. lactis & II \\
\hline$B$ & CIP 54171, NCIB 3351 & $b$ & L. mesenteriodes & VI \\
\hline$C$ & NCIB 9317 & $c$ & L. mesenteroides & VI \\
\hline$D$ & NCDO 543,829 & $d$ & L. cremoris & \\
\hline & NCDO 517,529, NCIB 3739 & & L. dextranicum & IV \\
\hline & NCIB 2706,3356, NCDO 812 & & L. dextranicum & V \\
\hline & NCIB $8013,8710,9319$ & & L. mesenteroides & VI \\
\hline & NCDO $522,523,1533$, ATCC 10830 & & L. mesenteroides & VI \\
\hline & $\begin{array}{l}\text { V } 16, \text { CIP } 54168, \text { CIP } 54170, \text { Le } 512-13 \text {, } \\
\text { Le } 512-17, \text { Le } 513-7, \text { Le } 513-12\end{array}$ & & L. mesenteroides & \\
\hline$E$ & NCDO $768^{\circ}, 882$ & $e$ & L. mesenteroides & VI \\
\hline$F$ & NCDO $803,870,871,872,873,885,886$ & $t$ & L. paramesenteroides & III \\
\hline & NCDO $955^{\circ}$, CIP $54169^{b}$ & & & \\
\hline$G$ & WL DI, WL BG31, WL B6, WL LAI, SC 122 & & L. oenos & VII \\
\hline
\end{tabular}

${ }^{a}$ Strain NCDO 768 fails to belong to group $e$ but does belong to group $d$.

${ }^{b}$ Strains NCDO 955 and CIP 54169 do not cross-react with serum anti-D-LDH.

spur when tested with any extract of the same group, but a precipitin line with a spur when tested with extracts of any strain belonging to a different group. Extracts of all groups except group $\mathrm{G}(L$. oenos) gave strong precipitin lines. The immunological remoteness of the D-LDH of L. oenos from the D-LDHs of other Leuconostoc species was in accord with the seemingly isolated taxonomic position of $L$. oenos in the genus suggested by the work of Garvie (5).

The polarity of the spurs obtained between extracts of strains belonging to different groups of identical specificity is shown in Fig. 2 and reveals the following order of decreasing similarity of the D-LDHs with respect to the homologous group $A: A>B>C>(D / F)>E>G$. Double diffusion tests with the anti-D-LDH against extracts of Lactobacillus species known to produce $\mathrm{D}-\mathrm{LDH}$ (6) revealed that some, but not all, heterofermentative lactobacilli possess weakly cross-reacting D-LDHs. Such cross-reactions were obtained with the extracts of $L$. buchneri, $L$. viridescens, and a variety of unnamed strains previously assigned to three distinct groups-HL I, HL II, and HL III $(6,7)$. On the other hand, extracts of $L$. fermenti, $L$. brevis (heterofermentative), $L$. jensenii, and $L$. jugurti (homofermentative) did not cross-react detectably. The order of decreasing similarity of these D-LDHs is: (all Leuconostoc strains) $>L$. viridescens $>$ L. buchneri $>$ (heterofermentative lactobacilli of groups HL I, HL II, and HL III).

Tests with the anti-G-6-P-DH showed that extracts of all the strains listed in Table 1 cross-reacted except strains of $L$. oenos and of 


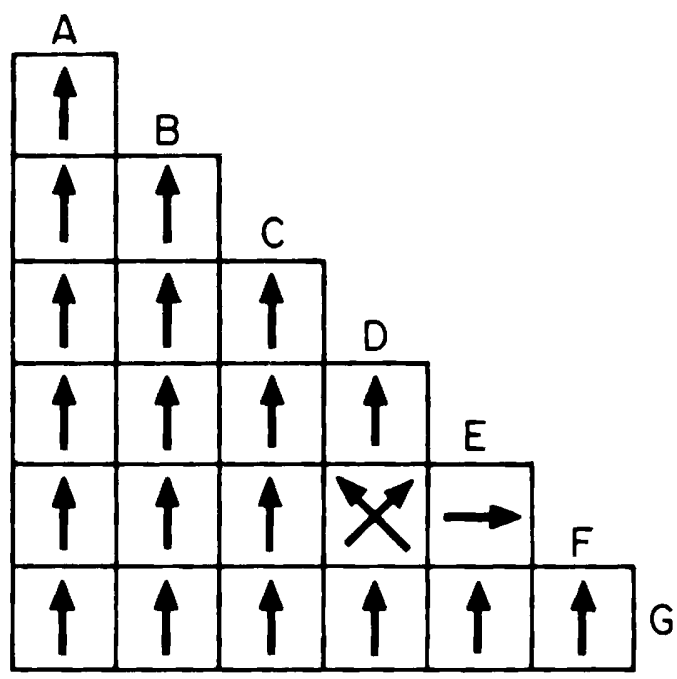

Fig. 2. Results of cross-reactivity experiments with the anti-D-lactate dehydrogenase between the different groups of identical specificity. Direction of arrows indicates the antigen which produces the spur in the corresponding paired comparison. Crossed arrows indicate a double spur formation. Details and discussion in reference 7 .

the lactobacilli. The failure of extracts of $L$. oenos to give detectable cross-reactions may have been caused by the low activity of G-6-P-DH in the cells which were grown with ribose rather than glucose as a fermentable substrate.

With respect to this antiserum, the strains of Leuconostoc fell into six groups of identical specificity: a homologous group $a$ which produces a continuous precipitin line with Leuconostoc lactis NCDO 546; and five heterologous groups $b, c, d, e$, and $f$ (Table 2).

The polarity of the spurs obtained between extracts of the different groups of identical specificity (Fig. 3) reveals the following order of decreasing similarity: $a>c>b>d>e>f$.

As shown in Table 2, the groups of Leuconostoc strains of identical specificity for D-LDH and for G-6-P-DH coincide with the exception of one strain, NCDO 768, which belongs to group $E$ (D-LDH) and to group $d$ (G-6-P-DH).

\section{DISCUSSION}

The remarkably close correlations between the immunological groupings obtained with antisera directed against D-LDH and against G-6-P-DH suggest that these two enzymes have undergone closely linked evolutionary changes within the genus Leuconostoc. Somewhat less detailed evidence which indicated linked evolutionary changes with respect to the $D$ - and
L-specific lactate dehydrogenases and the aldolase of lactic acid bacteria have been previously reported $(7,10)$.

Thus, the comparative immunological study of additional enzymes has strengthened rather than weakened the conclusions concerning evolutionary relationships among the lactic acid bacteria that were originally proposed mainly from the study of D-LDH and L-LDH among lactobacilli. It should be noted that all of the enzymes of lactic acid bacteria so far studied with respect to their immunological properties are ones that play central roles in the energyyielding metabolism of this microbial group and are therefore probably subject to severe evolutionary constraints.

In Table 2 the phenospecies of Leuconostoc which were proposed by Garvie $(4,5)$ on the basis of classical taxonomic criteria and the immunological groupings revealed in the present study are compared. The three groups of identical specificity $A a, F f$, and $G$ correspond precisely to three of the phenospecies recognized by Garvie-L. lactis, L. paramesenteroides, and $L$. oenos, respectively. On the other hand, the remaining groups of identical specificity show no such nice taxonomic correspondence. Strains assigned by Garvie to the type species, $L$. mesenteroides, fall into no less than four groups of identical specificity. Three of these groups, $B b, C c$, and $E e$, are small and contain only strains assigned to $L$. mesenteroides. The fourth group, $D d$, is very large (containing 22 of the 50 strains examined)

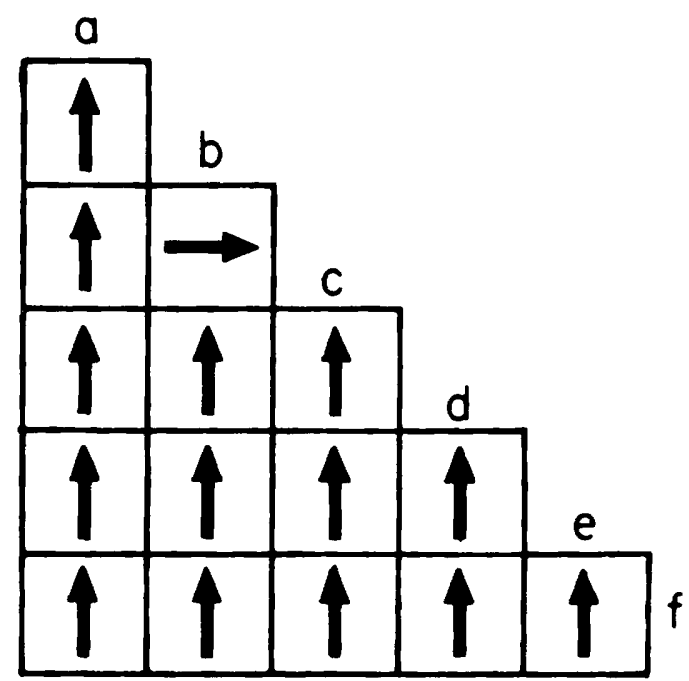

FIG. 3. Results of cross-reactivity experiments with the anti-glucose-6-phosphate dehydrogenase between the different groups of identical specificity. See legend of Fig. 2 and reference 7 for explanations. 

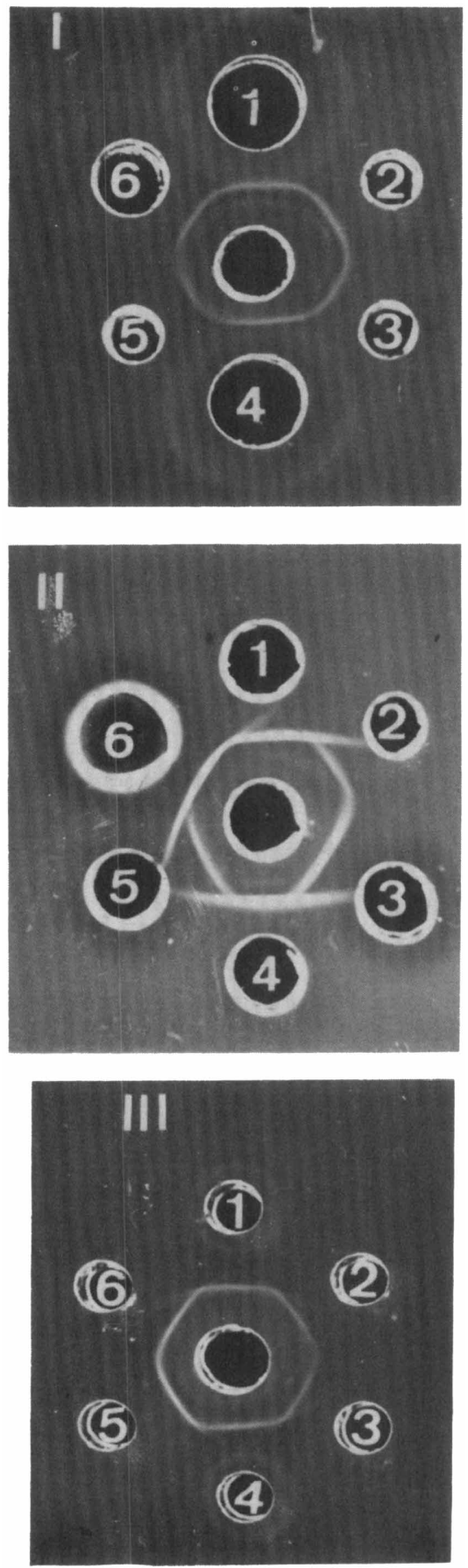

FIG. 4. Results of double diffusion experiments with the anti-D-LDH serum among Leuconostoc species. $I$. The outer wells contain crude extracts ( 0.5 unit of $D$ LDH activity) of L. mesenteroides NCDO 523 (wells 1 and 4), L. cremoris NCDO 829 (well 2), L. dextranicum NCDO 812 (well 3), L. dextranicum NCDO 529 (well 5), and L. mesenteroides NCDO 1533 (well 6). II. The outer wells contain crude extracts ( 0.5 unit of $D-L D H$ activity) of $L$. mesenteroides NCIB 9317
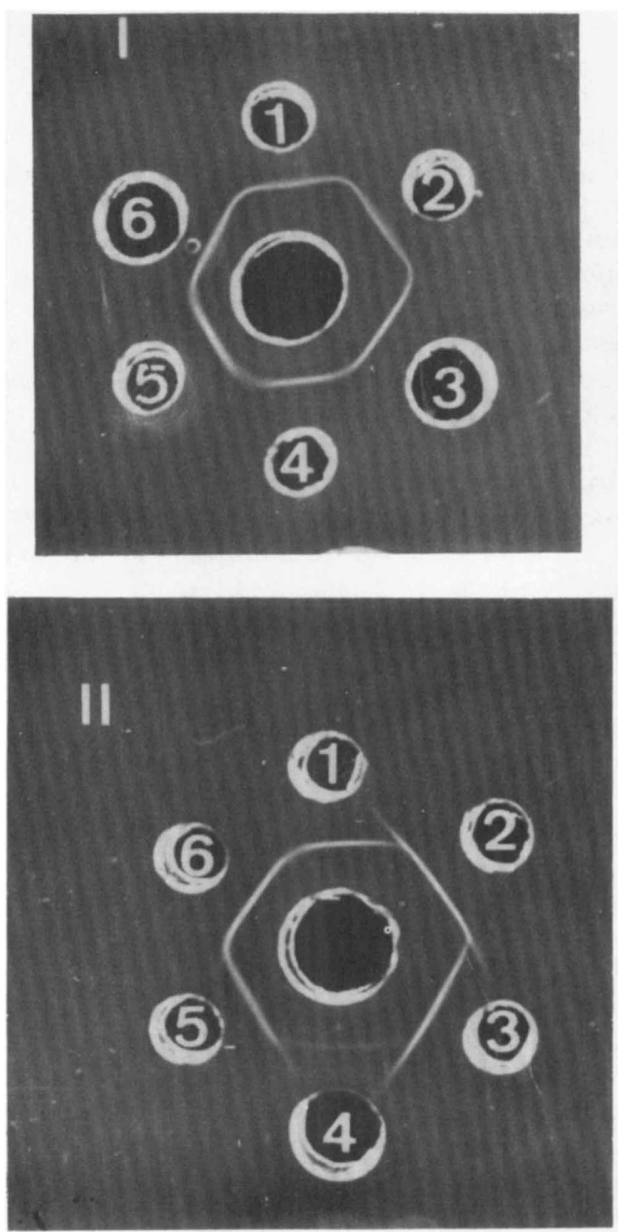

Fig. 5. Results of double diffusion experiments with the anti-G-6-P-DH serum among Leuconostoc species. 1 . The outer wells contain crude extracts $(0.5$ unit of G-6-P-DH activity) of L. dextranicum NCDO 529 (wells 1 and 4), L. mesenteroides NCDO 1533 (well 2), L. dextranicum NCDO 812 (well 3), L. mesenteroides NCDO 522 (well 5), and L. cremoris NCDO 829 (well 6). II. The outer wells contain crude extracts (0.5 unit of G-6-P.DH activity) of L. mesenteroides CIP 54168 (well 1), L. lactis NCDO 549 (well 2), L. mesenteroides NCIB 3351 (well 3), L. paramesenteroides CIP 54169 (well 4), L. mesenteroides NCDO 882 (well 5), and L. mesenteroides NCDO 522 (well 6).

(wells 1 and 4), L. mesenteroides NCIB 8710 (well 2), L. mesenteroides NCIB 8013 (well 3), L. dextranicum NCIB 3356 (well 5), and L. mesenteroides NCIB 3351 (well 6). III. The outer wells contain crude extracts ( 0.5 unit of D-LDH activity) of L. paramesenteroides NCDO 803 (wells 1 and 4), L. dextranicum NCDO 529 (well 2), L. dextranicum NCDO 812 (well 3), L. mesenteroides NCDO 522 (well 5), and $L$. cremoris NCDO 829 (well 6). 
and includes strains representative of three different species $-L$. cremoris, $L$. dextranicum, and $L$. mesenteroides (Fig. 4 and 5). It should be noted that 15 of the 22 strains placed in group $D d$ had been previously characterized by Garvie, so that their specific assignments are not open to question in terms of current taxonomic criteria. Furthermore, the phenotypic differences between at least two of these species, $L$. cremoris and $L$. mesenteroides, are numerous: strains of the former ferment only glucose, galactose, and lactose whereas strains of the latter may ferment as many as 16 of the 17 substrates tested. The physiological basis for making a specific separation between $L$. cremoris and $L$. mesenteroides therefore appears to be well founded.

However, our results suggest the possibility of a different taxonomic interpretation and treatment. It is conceivable that a substantial fraction of the genome of all strains belonging to group $D d$ is similar, coding for many shared isofunctional enzymes (including D-LDH and G-6-P-DH). In this sense, the strains of group Dd might be considered members of a single genospecies-"bacteria that are phenotypically heterogeneous but genetically related by virtue of descent from a common ancestor" (16). The manifest phenotypic differences among them would reflect differences with respect to a certain portion of the genome; such genetic divergence might have arisen either through acquisition by some representatives of additional exogenous genetic material, or by a loss of certain genetic functions as a result of environmental adaptation. It should be noted that some of the striking phenotypic differences within group $D d$ that were revealed by Garvie are clearly correlated with differences in habitat. For example, $L$. cremoris, found only in milk and milk products, ferments only lactose and its constituent monosaccharides, while $L$. mesenteroides, a species of much wider and more varied natural distribution, has much wider fermentative abilities.

\section{ACKNOWLEDGMENTS}

We wish to thank R. Y. Stanier for helpful discussion and assistance during the preparation of the manuscript and E. I. Garvie, J. Peynaud, M. Rogosa, and M. E. Sharpe for providing us some of the strains used in the work. This work was supported by research funds of the University Paris VII.

\section{REPRINT REQUESTS}

Address reprint requests to: Dr. Mireille Hontebeyrie, Service De Physiologie Cellulaire, Institute Pasteur, 28 rue du Dr. Roux, 75015 Paris, France.

\section{LITERATURE CITED}

1. Cocks, G. T., and A. C. Wilson. 1972. Enzyme evolution in the Enterobacteriaceae. J. Bacteriol. 110:793-802.

2. De Man, J. C., M. Rogosa, and M. E. Sharpe. 1960. A medium for the cultivation of lactobacilli. J. Appl. Bacteriol. 23: 130-135.

3. Fine, I. M., and L. A. Costello. 1963. The use of starch electrophoresis in dehydrogenase studies, p. 958-972. In S. P. Colowick and N. O. Kaplan (ed.), Methods in enzymology, vol. 6, Academic Press Inc., New York.

4. Garvie, E. I. 1960. The genus Leuconostoc and its nomenclature. J. Dairy Res. 27:283-292.

5. Garvie, E. I. 1967. Leuconostoc oenos sp. nov. J. Gen. Microbiol. 48:431-438.

6. Gasser, F. 1970. Electrophoretic characterization of lactic dehydrogenases in the genus Lactobacillus. J. Gen. Microbiol. 62:223-239.

7. Gasser, F., and C. Gasser. 1971. Immunological relationships among lactic dehydrogenases in the genera Lactobacillus and Leuconostoc. J. Bacteriol. 106:113-125.

8. Grabar, P., and C. A. Williams. 1955. Méthode immunoelectrophorétique d'analyse de mélanges de substances antigéniques. Biochim. Biophys. Acta. 17:67.

9. Hontebeyrie, M., and F. Gasser. 1973. Séparation et purification de la D-lactico-deshydrogénase et de la glucose-6-phosphate déshydrogénase de Leuconostoc lactis. Etude de quelques propriétés. Biochimie 55:1047-1056.

10. London, J., and K. Kline. 1973. Aldolase of lactic acid bacteria: a case history in the use of an enzyme as an evolutionary marker. Bacteriol. Rev. 37:453-478.

11. London, J., E. Y. Meyer, and S. Kulczyk. 1971. Comparative biochemical and immunological study of malic enzyme from two species of lactic acid bacteria: evolutionary implications. J. Bacteriol. 106:126-137.

12. London, J., E. Y. Meyer, and S. Kulczyk. 1971. Detection of relationships between Streptococcus faecalis and Lactobacillus casei by immunological studies with two forms of malic enzyme. J. Bacteriol. 108:196-201.

13. Mandell, J. D., and A. D. Hershy. 1960. A fractionating column for analysis of nucleic acids. Anal. Biochem. 1:66-77.

14. Prager, E. M., and A. C. Wilson. 1971. The dependence of immunological cross-reactivity upon sequence resemblance among lysozymes. I. Micro-complement fixation studies. J. Biol. Chem. 246:5978-5989.

15. Prager, E. M., and A. C. Wilson. 1971. The dependence of immunological cross-reactivity upon sequence resemblance among lysozymes. II. Comparison of precipitin and micro-complement fixation results. J. Biol. Chem. 246:7010-7017.

16. Ravin, A. W. 1963. Experimental approaches to the study of bacterial phylogeny. Amer. Natur. 97:307-318.

17. Stanier, R. Y., D. Wachter, C. Gasser, and A. C. Wilson. 1970. Comparative immunological studies of two Pseudomonas enzymes. J. Bacteriol. 102:351-362.

18. Whiteside, T. L., A. J. De Siervo, and M. R. J. Salton. 1971. Use of antibody to membrane adenosine triphosphatase in the study of bacterial relationships. $J$. Bacteriol. 105:957-967. 